\title{
Propriedade, estrutura fundiária e desenvolvimento (rural)
}

\author{
PEDRO RAMOS
}

“O desenvolvimento terá de ser cultural no século XXI, ou não será”.

Cuéllar, 1997: 306.

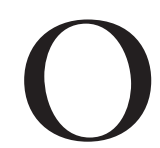

TERMO “desenvolvimento rural sustentável” vem sendo utilizado recentemente para designar a melhoria da qualidade de vida das populações rurais e a exploração do solo ou das atividades agropecuárias com preservação/recuperação ambiental. Tem sido empregado como uma novidade conceptual e as realidades a que se remete vêm sendo merecedoras de preocupações e de políticas não apenas nos países subdesenvolvidos.

O texto que se segue partiu de uma resistência inicial: não se entendia adequado ou correto tal expressão, pois o processo de desenvolvimento parece algo sempre geral, não cabendo qualquer distinção. A lembrança de que existem enfoques análogos (desenvolvimento urbano, regional, local etc.) logo se mostrou insuficiente como justificativa, acabando por estimular uma reflexão mais cuidadosa sobre o tema do desenvolvimento, a qual exigiu a retomada de antigas leituras e a realização de novas. O resultado das reflexões feitas a partir de tais leituras foi sistematizado na forma a seguir.

Na primeira parte, recorre-se às novas concepções sobre o desenvolvimento e às implicações destas, especialmente no tocante às relações dos homens entre si e com a Natureza, seja quando consideradas apenas no caso dos países subdesenvolvidos, seja quando pensadas em um contexto global. Destaca-se o esforço de incorporação da Cultura, o que é hoje amplamente reconhecido por organismos internacionais e por estudiosos da história e da situação atual dos países periféricos, as quais não podem ser devidamente compreendidas quando se esquece as relações destes com os países centrais.

Neste percurso, destaca-se na segunda parte que uma das principais distinções entre o mundo desenvolvido e o não-desenvolvido diz respeito exatamente à associação entre as formas de apropriação e exploração dos recursos não-reprodutíveis, e as implicações disto para a distribuição da renda e riqueza social, bem como para um uso menos predatório de tais recursos. Reconhece-se que as atividades agropecuárias têm especificidades que demandam a criação e a sustentação de políticas que regulam as relações entre o capital, o trabalho (recursos re- 
produtíveis) e a terra, exatamente porque esta é o principal recurso não-reprodutível, embora não o único. A terceira parte contém breves comentários de trabalhos que apresentam novas evidências empíricas sobre o que vem sendo chamado de "desenvolvimento rural", conceito que, em última análise, pode ser visto como uma síntese dos conceitos de "desenvolvimento humano" e "desenvolvimento sustentável".

De cada parte destaca-se um personagem ou autor principal, que "dialogam" nas observações finais.

\section{As relações Homem/Natureza nas novas concepções sobre o desenvolvimento: a autocrítica dos economistas}

A relação entre a apropriação e a utilização dos recursos naturais - particularmente da terra - com o desenvolvimento das nações tem sido reconsiderada recentemente, no contexto de reflexões que vêm buscando superar as reconhecidas limitações e simplificações das teorias e análises, principalmente dos economistas. Embora tais reflexões tenham em conta também a situação dos países desenvolvidos, elas parecem ser mais importantes quando se referem ao caso dos países subdesenvolvidos, pois é nestes que “a terra é ainda o mais importante meio de produção (...); seu estatuto é muitas vezes determinado por considerações culturais de alocação, uso e gestão ambiental" (Cuéllar, 1997: 45), e nos quais é necessário "uma economia e uma política renovadas" que tenham em conta a situação de "seus produtores agrícolas e [de] suas sociedades rurais" (Perroux, 1981: 252). Em outras palavras, é particularmente nestes países que se torna fundamental discutir as relações entre a propriedade e a utilização dos "elementos da produção", levando em consideração que alguns são reprodutíveis e outros não.

Polanyi (1980: 181) aborda tal problemática, partido do reconhecimento de que "a função econômica é apenas uma entre as muitas funções vitais da terra. Esta dá estabilidade à vida do homem; é o local da sua habitação, é a condição da sua segurança física, é a paisagem e as estações do ano". Na análise histórica que fez, constatou que "o caso do dinheiro revelou uma analogia muito real à do trabalho e à da terra. A aplicação da ficção da mercadoria a cada um deles levou à sua inclusão efetiva no sistema de mercado" (p. 195). Contudo, como elementos fundamentais da produção, um "sistema de mercado auto-regulável” (itálico no original) somente existiria na hipótese de um funcionamento dos mercados destes elementos que não ameaçasse a sociedade. Como está ameaça foi (e é) inegável, fica caracterizado o "credo" da economia liberal. Cumpre resgatar sua observação, feita no capítulo 15 (apropriadamente intitulado "Mercado e Natureza"), que "a comercialização do solo foi apenas um outro nome para a liquidação do feudalismo" (p. 182) e sua argumentação é suficientemente clara para mostrar que, a partir de então, a apropriação/propriedade e estrutura fundiária sempre guardaram relação com o trabalho, sendo inquestionavelmente reguladas pelos 
governos europeus, dadas as óbvias relações entre estes dois "mercados". Sua análise desenvolve-se para incorporar uma consistente explicação da criação e sustentação das políticas agrícolas nos países desenvolvidos e a busca da autosuficiência agrícola (1). Uma comparação desta análise com a do primeiro livro de $O$ Capital permite constatar que estão sendo tratados os dois "equivalentes gerais" reprodutíveis (trabalho e dinheiro, também destacados por Keynes), e a terra, que não o é, o que implica a necessidade de um tratamento diferenciado.

Uma reflexão sobre a estrutura fundiária nos países subdesenvolvidos foi feita pela CEPAL logo depois desta obra de Polanyi. A contribuição de Prebisch e seus colegas cepalinos destacou que a estrutura fundiária concentrada dos países latino-americanos e caribenhos era um obstáculo ao desenvolvimento, pois restringia o mercado interno e perpetuava o dualismo da estrutura econômica de tais países. Contudo, devido às suas mais complicadas implicações políticas, este "componente" da análise parece não ter tido o mesmo alcance que outros. Ocorreu também que, no caso do Brasil, isto deu origem à tese estagnacionista (exposta por Celso Furtado) que pareceu equivocada principalmente porque o país entrou logo depois em um ciclo expansivo vigoroso, embora de curto prazo. Assim, a contribuição da análise cepalina quanto ao processo de industrialização/substituição de importações e a admissão da ajuda fornecida pelo capital estrangeiro acabaram servindo para legitimar as políticas governamentais e contribuíram sobremaneira para a fixação da idéia de que bastava se industrializar para se desenvolver. Reforçou este "nacional desenvolvimentismo" industrialista a incorporação da teoria do oligopólio, então em construção, que explicava a rigidez dos preços dos bens industriais face à flexibilidade dos preços dos bens o conhecido "deterioro dos termos de intercâmbio" (2).

No início dos anos 70 Celso Furtado se deu conta do "mito do desenvolvimento econômico", tendo primeiramente destacado a questão da esgotabilidade dos recursos naturais como impedimento à reprodução, na periferia, do estilo de vida dos países desenvolvidos. Fez isto insistindo na necessidade de romper com o passado no tocante à estrutura fundiária herdada (ver Furtado, 1978: cap. II). Depois, sua reflexão expandiu-se para incorporar um "enfoque interdisciplinar" e a questão cultural, e observou que "a terra, tanto quanto a capacidade do homem para produzir trabalho [passaram] a ser vistas do ângulo de seu valor de troca, como objetos de transações mercantis", indagando sobre "as relações entre a cultura como sistema de valores e o processo de desenvolvimento das forças produtivas, entre a lógica dos fins, que rege a cultura, e a dos meios, razão instrumental inerente à acumulação" (respectivamente, Furtado, 1981: 4 e 1984: 31). Para tanto, com certeza baseou-se em sua participação em uma reunião que discutiu a perspectiva de um "desenvolvimento integrado"(3).

Deste contexto é que Perroux (1981: 79) observou que "a distinção do ‘econômico' e do ‘social' supõe que o econômico pode ser nitidamente separado 
do social”, para, muitas páginas depois, observar que "a cultura, é a hierarquia social criada pelos valores culturais que presidem à atribuição dos papéis anteriores a toda análise econômica da produção e da repartição" (p. 285), o que inclui a questão da propriedade. Conclui sua obra destacando que se torna necessário dar conta de um projeto global comum que contemple três "subprojetos" no contexto da filosofia de um novo desenvolvimento, recusando a "classificação" disto como utopia, especialmente pelos economistas: a) a mobilização popular das vontades, onde cumpre papel fundamental o conteúdo da educação e do ensino; b) reformas das estruturas de consumo, de produção e repartição, tanto nos países desenvolvidos como nos em desenvolvimento; c) um desarmamento, geral e controlado, para se acabar com as "matanças coletivas" (p. 298-299).

Nos anos 80 uma outra comissão preocupou-se, sob os auspícios da ONU, com a questão do uso dos recursos naturais não-renováveis pelo homem. Embora tal preocupação já fosse manifestada desde 1972, foi apenas com a constituição da Comissão Mundial sobre Meio Ambiente e Desenvolvimento, em 1983, que se passou a produzir algo efetivo. Como se sabe, os trabalhos encerraram-se com a publicação, em 1987, do relatório Nosso futuro comum. Corretamente, a comissão recusou-se a aceitar que suas "considerações se limitassem apenas a 'questões ambientais"” (Comissão, 1991: XIII), percebendo que aquela questão envolvia aspectos mais complexos, e destacou a necessidade de discutir conceitos e noções usuais. Foi a partir de então que se disseminou pelo mundo o conceito de "desenvolvimento sustentável", hoje amplamente conhecido (4).

É de se observar, contudo, que isto não conduziu a comissão a uma reflexão específica ou destacada sobre as alternativas de uso do solo, nem mesmo quanto às formas de acesso à terra e, principalmente, como tal aspecto se articularia com a compreensão que o ser humano tem sobre este recurso natural, ainda mais quando se tem em conta que o relatório menciona os chamados "recursos livres" (água e ar) e não se pronuncia sobre o fato de que a terra não o seja, além da inconveniência de se tratar separadamente terra, água e ar. Em uma perspectiva de longo prazo, é óbvio que aqueles dois recursos também vêm deixando de ser livres, no sentido geralmente referido pelos economistas (5). Avançando nesta perspectiva, é também estranho a comissão reconhecer o problema da decrescente disponibilidade dos recursos não-renováveis e da pobreza mundial, mas destacar como primeiro "imperativo estratégico" das políticas ambientais e desenvolvimentistas a retomada do crescimento econômico (elevação da renda per capita) e apenas em segundo lugar mencionar a alteração da "qualidade do desenvolvimento". A leitura do relatório deixa claro que a comissão não desconhecia que a pobreza decorre fundamentalmente de um problema distributivo (6).

Entre março de 1993 e setembro de 1995, as reflexões sobre um "novo desenvolvimento" ganharam novo impulso em decorrência das reuniões da Comissão Mundial de Cultura e Desenvolvimento, formada por pensadores de di- 
versos países - entre os quais Celso Furtado, sob os auspícios da Unesco e do Secretariado Geral da ONU. O rico relatório final também parte do reconhecimento de que "a cultura [é] que define como as pessoas se relacionam com a natureza e com o meio ambiente físico, com a Terra e com o cosmos, e como expressam suas atitudes e suas opiniões sobre as formas de vida animal e vegetal", e observa que "a maioria da população pobre do mundo ainda vive em áreas rurais, algumas das quais ambientalmente frágeis, e depende de recursos naturais sobre os quais tem pouco controle" (Cuéllar, 1997: 33;295), alertando ainda para a necessidade de se ir além da consideração das variáveis quantificáveis na análise econômica, a qual, afinal, tem buscado dar conta das "razões e dos resultados do altruísmo, da confiança, da cooperação, da lealdade, da solidariedade, e até mesmo da afeição e do amor" (p. 347).

Tais reflexões estão associadas à conclusão a que chegou Celso Furtado: “o verdadeiro desenvolvimento dá-se nos homens e nas mulheres, tem importante dimensão política" e a distinção fundamental entre desenvolvimento e subdesenvolvimento está associada aos esforços e resultados das ações no plano político para diminuir a heterogeneidade social que o modo capitalista de produção gera (Furtado, 1992: 75;39, respectivamente) (7).

A autocrítica dos economistas, especialmente quanto ao reconhecimento dos limites e insuficiências de suas elaborações teóricas, é importante, pois significa um esforço de superação do mal causado pela indelével influência que tais elaborações exerceram na cultura da civilização ocidental nos últimos 200 anos.

\section{Reconsiderando as atividades agropecuárias e especificando as razões para pensar um "desenvolvimento rural"}

A mencionada autocrítica dos economistas pode ser considerada uma das fontes de inspiração para trabalhos que, dada a impossibilidade de se tratar a estrutura fundiária e sua alteração como "variável" dos modelos na teorização econômica, tem buscado analisar a experiência histórica dos países industrializados para discutir as relações entre aquela estrutura e um desenvolvimento social menos heterogêneo (8). Entre esses trabalhos pode-se citar o de Veiga (1991), o de Abramovay (1992), e o de Romeiro (1994), para mencionar apenas os mais conhecidos em língua portuguesa (9). Não há dúvida de que muito antes disso historiadoras e historiadores produziram trabalhos que trataram, direta ou indiretamente, deste tema ou daquela relação. Está fora de cogitação comprovar esta afirmação.

A contribuição da CEPAL não foi a única referência para as reflexões sobre as relações entre estrutura agrária e desenvolvimento no caso dos países subdesenvolvidos. Como se sabe, já desde o final dos anos 50 foi intenso o debate sobre a reforma agrária na América Latina e dele participou ativamente José 
Gomes da Silva, que dirigiu instituições incumbidas de implementar programas de alteração da estrutura agrária e de desenvolvimento agrícola no Brasil e na América Latina.

Nessa mesma época, consolidava-se entre os economistas especializados nas questões do chamado setor agropecuário uma elaboração teórico-histórica que fala das "funções da agricultura no processo de desenvolvimento". A contribuição que se tornou mais amplamente conhecida foi a de Johnston \& Mellor (1961), que é ainda utilizada.

Por isso mesmo, cabe logo apontar a crítica que se pode fazer a tal elaboração: ao abordar assim a relação entre as atividades agropecuárias e o processo de desenvolvimento. Essa perspectiva "funcionalista" deixou em segundo plano as alternativas de posse e uso do solo no cumprimento daquelas "funções" e acabou contribuindo para consolidar a já mencionada visão de que o desenvolvimento se limita ao processo de urbanização-industrialização: à agropecuária caberia transferir renda e liberar mão-de-obra e, ao mesmo tempo, constituir mercado para aquele processo; gerar divisas para a economia industrializar-se/desenvolver-se ao mesmo tempo em que deveria fornecer alimentos e matérias-primas em quantidade e a preços adequados para tanto etc. Não há dúvida de que, assim, ela acabou sendo vista como uma grande "externalidade" àquele processo. Mais ainda, fica evidente a confusão que se estabeleceu entre desenvolvimento agrícola e desenvolvimento agrário, e o não-destaque para um "desenvolvimento rural" $(10)$.

Esta crítica não pode ser dirigida apenas aos economistas, sejam ou não especializados em questões agrárias/agrícolas, estejam vivos ou mortos (11). A visão de que "rural" é sinônimo de rústico ou de atraso tem enraizamento cultural: como observado em Cuéllar (1997: 288), "na virada do século, os pensadores clássicos da modernidade tratavam a cidade como uma criação cultural e como um motor do desenvolvimento (Max Weber, Georg Simmel)". Cabe atentar para o fato de que, em português, os termos civilização e urbanização conduzem à conclusão de que civilizado é o "cidadão", ou seja, o habitante da cidade - o "indivíduo que goza dos direitos civis e políticos de um Estado". Neste sentido, pode passar desapercebido que utilizar a expressão "resgatar a cidadania" não faz sentido quando referida a habitantes de áreas rurais (12).

Embora tenha utilizado as referidas funções em uma obra, Silva (1971) tratou muitos dos aspectos anteriormente abordados para buscar evidenciar a importância de uma estrutura fundiária desconcentrada, ou seja, da reforma agrária no processo de desenvolvimento de um país. Mencionou trabalhos que discutiram a inexistência de associação positiva entre tamanho de propriedade e rendimento por área (p. 128-129) e chamou a atenção para o fato de que, no Brasil, dois aspectos dificultavam a realização de uma reforma agrária: a não-distinção das figuras sociais, pois os industriais, comerciantes, profissionais liberais, políti- 
cos etc. eram ao mesmo tempo proprietários fundiários, associando isto ao fato de que a terra acabava sendo um "seguro contra a inflação" (p. 240-24l). É óbvio que isto remete novamente à questão de como se vê a terra, agora tendo em conta uma economia na qual as figuras se superpõem e ocorre um processo inflacionário intenso. Talvez seja por isso que ele tenha deixado claro um pouco antes que a reforma agrária implicaria a "criação massal e imediata de novos donos de terra com condições de se transformarem em produtores rurais bem sucedidos" (p. 183) (13).

Além da CEPAL, outros organismos internacionais preocuparam-se com as relações entre a estrutura fundiária e o desenvolvimento e, assim, acabaram discutindo um "desenvolvimento rural".

A FAO, que já organizara em 1966 uma conferência mundial sobre reforma agrária, organizou em 1979 uma outra, intitulada "Reforma Agrária e Desenvolvimento Rural". A ela compareceram mais de 1500 políticos e dirigentes públicos de todo o mundo, destacando-se presidentes e ministros de países periféricos. Com a contribuição dos participantes observou-se que a "luta contra a pobreza não é somente uma questão de técnicas de produção e de inversão de capitais. É uma questão eminentemente política. Engloba questões relativas à atual distribuição da riqueza e da localização atual do poder dentro das nações e entre elas" e que "a propriedade da terra é o eixo do sistema sócio-econômico rural, em que as relações entre os indivíduos estão regidas pelo objetivo de definir os direitos e responsabilidades relativos ao acesso à terra e à utilização desta" (Dé Carli, 1980: 20;34). Como observou um político brasileiro que dela participou, na conferência foram tratados reforma agrária e desenvolvimento rural como processos complementares, pois "aceita-se também universalmente que em toda a estratégia de reforma agrária e desenvolvimento rural é requisito indispensável a um acesso mais justo à terra, à água e demais recursos agrícolas", assim como políticas internacionais auxiliares à alteração da situação interna nos países subdesenvolvidos (Dé Carli, 1985: 248). Na conferência observou-se também que a reforma agrária ("terra para quem a cultiva") não é condição suficiente para o desenvolvimento rural, sendo necessárias políticas para tanto (14).

Assim, são as alterações na posse/uso da terra, ou seja, na estrutura fundiária, que permitem associar desenvolvimento sócio-econômico com desenvolvimento agrário-agrícola. A junção destes dois "conjuntos" é que justifica distinguir um "desenvolvimento rural" (15). Isto apenas pode ocorrer na esfera da Política, exatamente porque as especificidades da agropecuária constituem a justificativa para as políticas (públicas) a ela voltadas, as quais são, ao mesmo tempo, políticas para aquele desenvolvimento. Tais políticas são necessariamente específicas, pois tratam de aspectos particulares e visam a objetivos distintos (renda/preços, ambientais, tecnológicas, de saúde, educação etc.), e destinam-se a manter e/ou a alterar realidades ou situações concretas. 
As referidas especificidades podem ser sintetizadas em duas perspectivas: a do processo de produção (ou clássica/marxista) e a do processo de consumo (neoclássica/keynesiana).

Quanto à primeira, destaca-se a inegável (maior) importância da Natureza ou dos fenômenos naturais no processo de produção agropecuário, que o torna de maior risco quando comparado ao industrial. Em outras palavras, a interferência das condições naturais ou de elementos não-controláveis pelo homem pode causar tanto empobrecimento quanto enriquecimento "injustos", e dizem respeito à rigidez do ciclo produtivo, à territorialidade da produção (locais apropriados), à sazonalidade, aos excessos e insuficiências das colheitas etc. Tais especificidades lembram a análise fisiocrática e explicam a menor agregação de valor ou a diferença entre tempo de produção e de trabalho apontada por Marx (16).

Quanto à segunda, cabe reconhecer que a participação do consumo de bens de origem agropecuária é decrescente na expansão dos mercados. Ou seja, a elasticidade-renda da demanda ou a demanda efetiva de bens relacionados às necessidades humanas básicas (comer, abrigar-se, proteger-se) relacionam a expansão deste mercado mais ao crescimento populacional do que às elevações de renda. Isto reforça o posicionamento de que a fome é inaceitável do ponto de vista de utilização dos recursos naturais pelo homem, quaisquer que sejam os padrões de consumo no interior de um país - ou no mundo. Assim, paradoxalmente, são os próprios instrumentos da análise neoclássica que explicam a "injustiça" do não-acesso a tais bens: os desejos humanos, neste caso, não são ilimitados, o que Marshall deixou devidamente explicitado.

A consideração destas “assimetrias” entre agricultura/indústria e o fato de a fome ser fundamentalmente um fenômeno presente no mundo subdesenvolvido implicam reconhecer que "o novo desenvolvimento é uma reivindicação de reestruturação total das nações menos desenvolvidas e do mundo", no qual deve ser tido em conta a "dimensão espacial e social" daquelas "assimetrias", não se limitando as reflexões à idéia de que se deve transpor, para os países subdesenvolvidos, a "experiência européia" (Perroux, 1981: 241;252;257, com itálicos no original).

Destaca-se ser a alteração estrutural, seja pacífica, seja violenta, que explica, na análise dos casos na história mundial, a criação e a manutenção das políticas destinadas às atividades agropecuárias ou ao que vem sendo chamado de desenvolvimento rural. Em outras palavras, são as lutas sociais que determinam a criação de instituições mediadoras/apaziguadoras. Se os países desenvolvidos apresentam menores disparidades territoriais e sociais, é exatamente aquela alteração que explica tal fato, o que Silva (1971: 18-19; 98-102) tinha muito claro ao apontar a insuficiência da política tributária para provocar aquele tipo de alteração no caso brasileiro (17). Foi para consolidar e expandir esta visão que ele e outros conterrâneos criaram a Associação Brasileira de Reforma Agrária (ABRA). 
Finalmente, há outro aspecto que deve ser considerado quanto à distinção urbano/rural. Para alguns autores, a cidade beneficia-se das "economias de aglomeração", o que supostamente permitiria uma vida de menor custo, dada a concentração espacial da oferta de bens e serviços (privados e/ou públicos) e de mercados compradores/consumidores. O reconhecimento desse aspecto levou Weitz (1978: 171) a admitir a necessidade de criar "cidades rurais", destacando que os "três principais aspectos do processo de desenvolvimento que afetam, diretamente, o indivíduo são: emprego, serviços e relacionamentos sociais". Contudo, recentemente isto tem sido posto em discussão, já que os males da cidade se tornaram "mais visíveis: a proliferação das classes subalternas, a mendicância, as drogas, o crime, a violência, o ódio e a baixa cultura de massa", além de o reconhecimento de que "as populações das cidades perdem freqüentemente o contato com o meio ambiente" (Cuéllar, 1997: 289; 288).

\section{Estrutura fundiária e desenvolvimento rural: algumas evidências empíricas}

O objetivo deste último tópico é, de maneira bastante sintética, destacar alguns trabalhos que coletaram, apresentaram e discutiram dados levando em conta as idéias e/ou perspectivas consideradas nas partes anteriores.

A ABRA vem recentemente publicando artigos que se preocupam em evidenciar a importância da agricultura familiar no Brasil e as relações disto com um “desenvolvimento rural sustentável”, não cabendo aqui uma menção particular a trabalhos e a autores (18). O fato é que se reconhece hoje amplamente as vantagens sociais de uma estrutura fundiária não-concentrada ou de uma exploração da terra por famílias de trabalhadores/proprietários.

Contudo, o destaque para aspectos particulares relacionados a informações e dados sobre o desenvolvimento rural é preocupação antiga. Em 1980 a revista da ABRA publicou um artigo que estudou cuidadosamente a associação entre mortalidade infantil e estrutura agrária no Rio Grande do Sul, no mesmo número em que José Gomes da Silva escreveu sobre "terra e qualidade da vida rural" (Ver Victora \& Blank, 1980; Silva, 1980).

Tal tema foi retomado recentemente por Rodolfo Hoffmann. Em artigo inspirado nos trabalhos há pouco mencionados, mas ampliando a base de dados, inclusive em termos geográficos, constatou que há indicações da existência de uma relação muito forte entre as variáveis indicadoras do desenvolvimento humano (saúde, educação, esperança de vida etc.) e a desigualdade da distribuição da posse da terra. Cuidadosamente, observou que tal associação não significa apontar relação de causalidade e evitou utilizar o termo desenvolvimento rural, mas concluiu que a desigualdade da estrutura fundiária "condicionou a formação de toda a estrutura sócio-econômica na microrregião, estabelecendo caracte- 
rísticas (inclusive a qualidade e a distribuição da educação) que até hoje têm forte influência na taxa de mortalidade infantil e na esperança de vida ao nascer" (Hoffmann, 2001: 9).

Hoffmann vem também há muito discutindo outros aspectos da economia agrária no Brasil, e é reconhecido especialista na análise da distribuição de renda, particularmente quando remetida àquela economia. Em artigo publicado em 1986, sob o modesto título "Contribuição ao estudo da concentração da produção agropecuária no Brasil em 1975 e 1980", abordou a problemática da existência ou não de economias de escala nas atividades agropecuárias, utilizando para tanto dados sobre 19 culturas retirados dos censos agropecuários naqueles anos. Constatou que "diferentemente do que ocorre na indústria, parecem ser bastante limitadas as atividades agrícolas onde há economias de escala" e não deixou de observar que "o pequeno proprietário rural se mantém como tal mesmo sem receber a renda da terra ou juros sobre o capital que emprega" (Hoffmann \& Silva, 1986: 158). Embora se possa discutir o termo "capital" utilizado nesta frase, mais importante é associar tais afirmações com as discussões feitas nos tópicos anteriores, inclusive quanto à questão da racionalidade do agricultor proprietário.

Utilizando a noção de economia de escala de maneira diferente ou nãorigorosa, e igualmente servindo-se de dados censitários, restritos ao Nordeste, em outro trabalho concluiu que "uma redistribuição que garanta a todas as famílias o acesso à terra elevaria o lucro $($ sic $)$ por hectare e por estabelecimento, vindo a proporcionar uma renda familiar mais elevada, mostrando que a redistribuição de terras é uma política importante e eficaz no combate à pobreza na região" (Barros et al., 2000: 677).

\section{Observações finais}

Neste trabalho teve-se como preocupação central mostrar que a atual discussão sobre desenvolvimento rural sustentável faz sentido quando inserida nas reflexões contemporâneas que os pensadores de diversas formações vêm fazendo sobre o processo de desenvolvimento, pensado nacionalmente ou não. Destacou-se que o tema tem particular interesse quando remetido à situação dos países subdesenvolvidos, pois é nas áreas rurais destes que se encontra a maior parte da população mundial que foi excluída daquele processo, o qual durante muito tempo foi confundido com o processo de urbanização/industrialização. Mostrou-se que isto teve enraizamento cultural, já que se cristalizou a visão de que rural significa atraso e conservantismo, tendo predominado até hoje um economismo e um racionalismo reducionistas nos quais a preocupação com a conservação do solo, do clima, enfim, da paisagem, ficou em segundo plano, tanto quanto a sua relação com a propriedade e estrutura fundiária. 
Assim, a atenção que vem sendo dada à exploração não-predatória dos recursos naturais por parte de pequenos e médios produtores rurais, algo hoje presente também nos países desenvolvidos, juntou-se às especificidades da produção agropecuária que, nem sempre de maneira explicitada, estão associadas à origem e à sustentação de políticas agrícolas em tais países. Estas foram, assim, políticas de desenvolvimento rural. Tal dimensão política do desenvolvimento e a necessidade de remover os entraves culturais à idéia de construir sociedades mais homogêneas nos países subdesenvolvidos têm sido destacadas por Celso Furtado, que, ademais, tem chamado a atenção para a importância de promover transformações nas relações sócio-econômicas e políticas no âmbito interno destes países, assim como nos dois sentidos em que se deve tomar aquelas relações quando pensadas internacionalmente.

A percepção de que a manutenção de estrutura fundiária concentrada, reforçada com a implementação de políticas agrícolas modernizadoras do latifúndio no Brasil, estiveram na base de um processo de crescimento econômico que manteve e mesmo ampliou a fome e a pobreza, a exclusão e a desigualdade social, e que, portanto, nada tiveram e nada têm de desenvolvimentistas - sequer no antigo sentido do termo - foi devidamente percebido por Silva. Os dados estatísticos apresentados por Hoffmann, e concernentes às atividades agropecuárias como não apresentando, de maneira generalizada, economias de escala, e os concernentes aos espaços rurais, deixam devidamente explícitos os elos entre os novos conceitos de "desenvolvimento humano" e de "desenvolvimento sustentável".

Nesta perspectiva, não se pode fugir da constatação de que constitui algo secundário nomear desta ou daquela forma as reflexões, iniciativas ou ações públicas e privadas voltadas às relações dos homens entre si e com a Natureza, neste ou naquele país, pois isto está relacionado à apropriação e à utilização da terra e dos chamados recursos não-renováveis de maneira global, algo que tem implicações muito mais importantes ou sérias do que a superação da dicotomia rural/ urbano.

\section{Notas}

1 A análise de Polanyi (1980: 182) sobre as transformações das estruturas agrárias nos países europeus antecipou a construção que Moore Jr. (1983) fez ao tratar do mesmo tema e propor uma tipologia (revolução vinda de cima, de baixo etc.). O termo mercados está entre aspas para ser fiel ao que se destaca da leitura da obra de Polanyi: ele está exatamente se opondo à idéia de um livre funcionamento dos mercados.

2 Outros aspectos componentes da análise cepalina, relacionados às especificidades do "setor agropecuário" e de seus produtos, serão discutidos a seguir. Martin Bronfenbrenner aponta 12 razões pelas quais os países buscam deixar de ser especializados em exportação de bens agropecuários, incluindo a contribuição de 
Prebisch. Ver seu artigo Agricultura de exportação no desenvolvimento econômico, em Froehlich (coord.), 1965: 127-139).

3 Esta reunião ocorreu em Quito, Equador, em agosto de 1979 e foi convocada pela Unesco, que solicitou a François Perroux a elaboração de um texto que abordasse o tema, "do ponto de vista da interrogação filosófica". O livro que se passa a citar refere-se a tal texto.

4 Como se sabe, o conceito de "desenvolvimento humano" também é recente e sua utilização na forma de índice ocorreu pela primeira vez em 1990, no relatório do Programa das Nações Unidas para o Desenvolvimento (PNUD).

5 Aqui cabe lembrar a afirmação de Say (1983: 337): a terra é (praticamente) o único agente da Natureza "que o homem conseguiu tornar propriedade privada e exclusiva e, conseqüentemente, cujo lucro tornou-se o lucro de um particular à exclusão de todos os demais".

6 Aqui cabe lembrar as observações de John Stuart Mill sobre os aspectos positivos da "condição estacionária", instigante e audacioso capítulo que termina com a idéia de que "as conquistas sobre as forças da Natureza conseguidas pelo intelecto e pela energia de pesquisadores científicos poderão se transformar em propriedade comum da espécie humana, bem como em meio para melhorar e elevar a sorte de todos". Ver Mill, 1986, v. II: 254.

7 Muito antes de Celso Furtado ter chegado a esta conclusão, um autor inglês deixou explícita a idéia de que o desenvolvimento não-necessariamente significaria "sempre mais" (mais bens, maior renda etc.), podendo, ao contrário, significar "sempre menos" (menos desigualdade, menos pobreza/fome etc.). Devo esta observação ao professor Paulo Cidade. Ver Seers, 1970.

8 Sobre a não-incorporação da alteração da estrutura fundiária, ou seja, da reforma agrária como "variável endógena" das teorias do desenvolvimento, ver Ramos, 1999.

9 O trabalho de Germer (1976), salvo uma provável desinformação ou desconhecimento, pode ser considerado pioneiro, pelo menos no caso de trabalhos produzidos no Brasil por brasileiros.

$10 \mathrm{Um}$ tratamento bastante rico da relação entre estrutura agrária não-concentrada e estabilidade social e da alteração do sistema de posse e uso da terra como desenvolvimento agrário e suas relações com o desenvolvimento social de diversos países asiáticos encontra-se em Froelich (coord.) 1965.

11 Depois de escrita a primeira versão do texto, tomei conhecimento de que um dos mais conhecidos sociólogos brasileiros vem propondo autocrítica semelhante: "Por muito tempo e para muitos, a sociologia rural foi mais uma sociologia da ocupação agrícola e da produtividade do que uma sociologia propriamente dita", tendo ficado presa "à suposição de que as populações rurais são populações retardatárias do desenvolvimento econômico e da História, supostas ilhas de primitivismo no suposto paraíso da modernidade". Ver Martins, 2000: 2. Antes disto, alguém já havia observado que "a crença na existência de duas únicas formas de racionalidade", uma camponesa, geral- 
mente associada ao atraso/conservantismo e a outra, capitalista, associada a um evolucionismo linear, não deixa de ser uma simplificação da realidade. Ver Neves, 1995: 22.

12 A consulta a um dicionário atualizado permite constatar que urbanizar significa "dar características urbanas, polir, civilizar" e que cidadania é a "qualidade de cidadão".

13 Como se sabe, foi Ignácio Rangel o autor brasileiro que tratou pioneiramente a terra como um "ativo" que recebe aplicação de recursos, muitas vezes ociosos, para proteção contra a corrosão inflacionária. Contudo, o conjunto de sua obra deixa claro que fez isto como um analista atento - mas não resignado - da realidade do capitalismo brasileiro, não sendo apropriado atribuir a ele um economismo reducionista quanto a como ver a terra em sociedades subdesenvolvidas, pois tratar a terra como um ativo financeiro acaba levando a isto. Alguém poderia alegar semelhança entre o "mercado" de terra rural e urbana, mas é óbvio ser indevido, pois o uso do solo urbano não é fundamentalmente produtivo, embora possa eventualmente sê-lo, estando seu mercado ou a especulação com ele associada principalmente com a criação de valor pelo trabalho humano, na forma de edificações as mais diversas.

14 Alguns anos antes de ter sido realizada a conferência da FAO (em 1971), um órgão regional brasileiro - o Banco do Nordeste - destacava a preocupação com o tema do desenvolvimento rural. Para tanto, estabeleceu uma cooperação internacional com o Setlement Study Center, de Israel, cujo diretor era Raanan Weitz, que escreveu um livro cujo sugestivo título é From peasant to farmer: a revolucionary strategy for development. Ver Weitz, 1978.

15 Este posicionamento é assumido em que pese a procedência da observação de Veiga (1997: 101) de que a história dos países desenvolvidos parece não justificar tal distinção, sendo mais adequado ver "o desenvolvimento rural (como) parte integrante de uma única dinâmica - sistêmica - de desenvolvimento" .

$16 \mathrm{O}$ reconhecimento disto não significa endossar a tese de que a agricultura familiar e uma estrutura de produção não-concentrada na agropecuária é justificada apenas pelos impedimentos ou dificuldades impostas à penetração do capital na agropecuária, o que, de resto, não deixa de ser uma outra versão do economismo anteriormente criticado. Tal tese, como se sabe, foi assumida por Goodman et al. (1990) e tem outras formulações que não cabe aqui detalhar. A propósito, "o movimento de evasão da agricultura" como resultado das especificidades de suas atividades e de seus bens foi tratado na história do pensamento econômico por Kusnets (1986: cap. 3).

17 Como se sabe, as políticas agrícolas modernizadoras da agropecuária no Brasil (particularmente entre 1969 e 1983) contribuíram sobremaneira para ampliar a concentração fundiária, de renda e de riqueza no país. Entre os inúmeros trabalhos que trataram do tema, cabe destacar o de Martine (1990), que também contém uma crítica sintética à idéia de que big is beautiful e big is eficient.

18 Os números recentes da revista da ABRA vêm discutindo estes e outros aspectos que enfatizam a problemática aqui tratada. Ver particularmente Reforma Agrária, números de jan./abr. 1993, de maio/dez. 1995 e de set./dez. 1999, jan./dez. 2000. As 
revistas do Instituto de Economia Agrícola da Secretaria da Agricultura e Abastecimento do Governo do Estado de São Paulo também vêm dedicando atenção a este tema.

Referências bibliográficas

ABRAmOVay, R. Paradigmas do capitalismo agrário em questão. São Paulo, Hucitec, 1992.

BARROS, R.P. de et al. Impactos da distribuição da terra sobre a eficiência agrícola e a pobreza no Nordeste. In: HENRIQUES, R. (org.). Desigualdade e pobreza no Brasil. Rio de Janeiro, IPEA, 2000.

BRONFENBRENNER, M. Agricultura de exportação no desenvolvimento econômico. In: FROEHLICH, W. (coord.), 1965.

COMISSÃO MUNDIAL sobre meio ambiente e desenvolvimento. Nosso Futuro Comum, 2. Ed. Rio de Janeiro, Ed. da Fundação Getúlio Vargas, 1991.

CUÉLLAR, Javier P. de (org.). Nossa diversidade criadora. Campinas, Papirus/Brasília, Unesco, 1997.

DÉ CARLI, G. Reforma agrária e desenvolvimento rural (FAO, 1979). Recife, ed. não indicada.

História da reforma agrária. Brasília, Ed. Gráfica Brasiliana, 1985.

FROEHLICH, W. (coord.). Posse e uso da terra, industrialização e estabilidade social, experiência e perspectivas na Ásia. Rio de Janeiro, Ed. Fundo de Cultura-Usaid, Aliança para o progresso, 1991.

FURTADO, C. Análise do "modelo" brasileiro, 6. ed. Rio de Janeiro, Civilização Brasileira, 1978.

Pequena introdução ao desenvolvimento: enfoque interdisciplinar, 2. ed. São Paulo, Cia. Editora Nacional, 1981.

Cultura e desenvolvimento em época de crise, 2. ed. Rio de Janeiro, Paz e Terra, 1984 1992.

Brasil: a construção interrompida, 2. ed. Rio de Janeiro, Paz e Terra,

GERMER, C.M. Análise histórica das relações entre desenvolvimento econômico e estrutura fundiária. Piracicaba, 1976. Dissertação (mestrado), Escola Superior de Agricultura Luiz de Queiróz, Universidade de São Paulo.

GOODMAN, D.; SORJ, B. \& WILKINSON, J. Da lavoura às biotecnologias: agricultura e industria no sistema internacional. Rio de Janeiro, Campus, 1990.

HOFFMANN, R. \& SILVA, L.A.C. da. Contribuição ao estudo da concentração da produção agropecuária no Brasil em 1975 e 1980. Revista de Economia Rural. Brasília, Sociedade Brasileira de Economia e Sociologia Rural (SOBER), 1986. 
HOFFMANN, R. A desigualdade da distribuição da posse da terra e o desenvolvimento humano. CONGRESSO BRASILEIRO DE ECONOMIA E SOCIOLOGIA RURALSOBER, 39. Anais. Recife (PE), 5 a 8 de agosto de 2001.

JOHNSTON, B.F. \& MELLOR, J.W. The role of agriculture in economic development. American Economic Review, v. LI, n. 4, p. 566-593, Sept. 1961.

KUSNETS, S. Crescimento econômico moderno: ritmo, estrutura e difusão, 2. ed. São Paulo, Nova Cultural (Coleção Os Economistas), 1986.

MARTINE, G. Fases e faces da modernização agrícola brasileira. Planejamento e Políticas Públicas. Brasília, Instituto de Pesquisa Econômica Aplicada (IPEA), v. 1, n. 3, p. 3-43, jun.1990.

MARTINS, J. de S. O futuro da sociologia rural e sua contribuição para a qualidade de vida rural. CONGRESSO MUNDIAL DA ASSOCIAÇÃO INTERNACIONAL DE SOCIOLOGIA RURAL, 10. Rio de Janeiro, 4 de agosto de 2000.

MILL, J. S. Princípios de Economia Política, v. II. São Paulo, Ed. Nova Cultural, $2^{\text {a }}$ ed. (Os economistas), 1986.

MOORE JR., B. As origens sociais da ditadura e da democracia. São Paulo, Martins Fontes, 1983.

NEVES, Delma P. Agricultura familiar: questões metodológicas. Reforma Agrária, revista da Associação Brasileira de Reforma Agrária, v. 25, n. 2/3, p. 21-36. maio/ dez. 1995.

PERROUX, F. Ensaio sobre a filosofia do novo desenvolvimento. Lisboa, Fundação Calouste Gulbenkian, 1981.

POLANYI, K. Agrande transformação: as origens de nossa época. Rio de Janeiro, Campus, 1980.

RAMOS, P. Agricultura e (sub)desenvolvimento: aspectos teóricos e elementos para uma reinterpretação do caso brasileiro. Reforma Agrária, v. 28, n. 1/2/3, jan./dez. 1998 e v. 29, n. 1, jan./ago. 1999.

ROMEIRO, Ademar R. Reforma agrária e distribuição de renda. In: STÉDILE, J.P. (coord.). A questão agrária hoje. Porto Alegre, Ed. da Universidade, UFRGS, 1994, p. 105-136.

SEERS, D. O desafio às teorias e estratégias desenvolvimentistas. Revista Brasileira de Economia, v. 24, n. 3, p. 5-50, jul./set., 1970.

SAY, J.B. Tratado de economia politica. São Paulo, Abril Cultural (Coleção Os Economistas), 1983.

SILVA, J.G. A reforma agrária no Brasil. Frustração camponesa ou instrumento de desenvolvimento? Rio de Janeiro, Zahar Editores, 1971.

Terra e qualidade da vida rural. Reforma Agrária, boletim da Associação Brasileira de Reforma Agrária, ano X, n. 6, nov./dez. 1980. 
VEIGA, J.E. da. O desenvolvimento agrícola: uma visão histórica. São Paulo, Edusp/ Hucitec, 1991.

Perspectivas nacionais do desenvolvimento rural. In: SHIKI, S. et al. (org.). Agricultura, meio ambiente e sustentabilidade do cerrado brasileiro. Uberlândia, Universidade Federal de Uberlândia. 1997.

VICTORA, C.G. \& BLANK, N. Mortalidade infantil e estrutura agrária no Rio Grande do Sul. Reforma Agrária, boletim da Associação Brasileira de Reforma Agrária, ano X, n. 6, nov./dez. 1980.

WEITZ, R. Uma nova estratégia de desenvolvimento rural. Fortaleza, Banco do Nordeste do Brasil, 1978.

Pedro Ramos, doutor em Economia Aplicada à Administração pela EAESP/FGV, é professor pesquisador do Núcleo de Economia Agrícola do Instituto de Economia da Universidade Estadual de Campinas, Unicamp, e da Universidade Metodista de Piracicaba. E-mail: peramos@eco.unicamp.br.

O autor agradece a Rodolfo Hoffmann pela crítica feita a uma versão preliminar do texto. 